\title{
Erythropoiesis and renal transplant pregnancy $^{1}$
}

Magee LA, von Dadelszen P, Darley J, Beguin Y. Erythropoiesis in renal transplant pregnancy.

Clin Transplantation 2000: 14: 127-135. (C) Munksgaard, 2000

Abstract: Objective. To examine erythropoiesis in renal transplant pregnancies.

Methods. Retrospective cohort study of 30 renal transplant cases and 30 age, smoking and parity-matched healthy controls with normal index pregnancy. Retrospective chart review and assay of frozen antenatal serum (for serum erythropoietin concentration [serum EPO]), transferrin receptor protein [TfR], ferritin, folate and B12) were performed. The linear regression equation for normal pregnancy controls was used to calculate predicted [serum EPO] and the observed/predicted $(\mathrm{O} / \mathrm{P}) \log$ [serum EPO] was plotted. The relationship between [serum EPO] and haemoglobin $(\mathrm{Hb})$ among transplant cases was considered to be different from that among controls if the slope of the $\mathrm{O} / \mathrm{P} \log$ [serum EPO] versus $\mathrm{Hb}$ regression was significantly different from zero.

Results. The transplant (14 cadaveric) to conception interval was (median [range]) 33.5 [4, 189] months. Immunosuppressants were azathioprine $(n=25)$, cyclosporine $(n=22)$ and/or prednisone $(n=25)$. Cases were more often primiparous (20 vs. 7 [controls]; $p=0.01)$, had pre-existent hypertension ( 20 vs. 0 [controls]; $\mathrm{p}<0.001$ ), developed new/increased hypertension or pre-eclampsia ( 28 vs. 0 [controls]; $\mathrm{p}<0.001$ ) and an antenatal rise in creatinine (14 vs. 2 [controls]; $\mathrm{p}<0.001)$. In early pregnancy, cases had similar EPO $(15.2$ [2.6, 84.6] vs. 15.7 [6.4, 41.0] [controls] $\mathrm{U} / \mathrm{L})$ but lower $\mathrm{Hb}(101[65,129]$ vs. 116 [106, 150] $\mathrm{g} / \mathrm{L} ; \mathrm{p}<0.001)$. Twenty-two $(73 \%)$ cases had $\mathrm{Hb}<100 \mathrm{~g} / \mathrm{L}$ (vs. 4 [controls]; $\mathrm{p}<0.0001)$; $\mathrm{Hb}$ was comparable at $6 \mathrm{wk}$ postpartum. With advancing gestational age (GA), Hb remained stable and serum EPO increased in both groups. The slope of the $\mathrm{O} / \mathrm{P} \log$ [serum EPO] versus $\mathrm{Hb}$ for transplant cases was significantly different from zero within both the 17-28 wk (slope \pm SEM: $0.010 \pm 0.002 ; \mathrm{p}<0.0001)$ and the $29-42$ wk GA categories $(0.006 \pm 0.003 ; \bar{p}=0.02)$. Cases showed smaller rises in serum TfR (change $481[-1471,2780])$ vs. 1119 [ $-698,4195]$ [controls] ng/mL; $\mathrm{p}=0.005)$.

Conclusions. Anaemia frequently complicates renal transplant pregnancies, in which serum EPO is inappropriately low and the rate of erythropoiesis blunted.

\section{Laura A Mageea, Peter von Dadelszen ${ }^{\mathrm{b}}$, John Darley ${ }^{\mathrm{c}}$ and Yves Beguin ${ }^{\mathrm{d}, 2}$}

${ }^{a}$ Nuffield Department of Obstetrics and Gynaecology, John Radcliffe Hospital, University of Oxford, Oxford, UK ${ }^{b}$ Department of Obstetrics and Gynaecology, University of Toronto, Toronto, Canada ${ }^{\mathrm{C}}$ Department of Haematology, John Radcliffe Hospital, University of Oxford, Oxford, UK

a Department of Haematology, University of Liege, Liege, Belgium

\author{
Key words: anaemia - erythropoietin - \\ pregnancy complications - renal \\ transplantation - serum transferrin receptor \\ protein
}

Corresponding author: Dr Laura A Magee, Assistant Professor of Medicine, Department of Medicine, Mount Sinai Hospital, 600 University Avenue, Suite 428, Toronto, ON M5B 2M3 Canada. Tel: + 1416586 4857; fax: + 1416586 8434; e-mail: laura.magee@utoronto.ca

Accepted for publication 4 October 1999
The World Health Organization defines anaemia in pregnancy as a haemoglobin $(\mathrm{Hb})$ concentration

\footnotetext{
${ }^{1}$ Abstract presented at the International Society for the Study of Hypertension in Pregnancy (ISSHP) Meeting, Kobe, Japan, October, 1998.

${ }^{2} \mathrm{YB}$ is a Senior Research Associate of the National Fund for Scientific Research (FNRS, Belgium).
}

less than $110 \mathrm{~g} / \mathrm{L}$ (1), although many clinicians use a cut-off of $100 \mathrm{~g} / \mathrm{L}$. Dilutional anaemia occurs in normal pregnancy because plasma volume increases to a greater degree than red blood cell mass (2).

As in non-pregnancy, anaemia in pregnancy may be caused by factors related to abnormal or decreased production and/or increased destruction 
of red blood cells. The oxygen sensor in the kidney controls production of erythropoietin (EPO), a glycoprotein growth factor that stimulates differentiation of erythroid progenitor cells in the bone marrow. There is an inverse relationship between serum EPO and $\mathrm{Hb}$ concentrations (3); in the presence of anaemia, EPO levels rise exponentially in both non-pregnancy (4) and normal pregnancy (5).

The John Radcliffe High Risk Obstetric Unit manages all renal transplant pregnancies within the Oxford Region. Progressive anaemia during pregnancy was observed in 3 women with stable creatinine concentrations. However, in a comprehensive literature review (6) of pregnancy outcome following renal transplantation (based on 2409 women and 3382 pregnancies from 1961 to 1994), anaemia was not mentioned as a problem.

The objective of this retrospective study was to examine, among gravidae with renal transplants, the prevalence of anaemia and the appropriateness of EPO production (as reflected by the relationship between antenatal serum EPO and $\mathrm{Hb}$ ). Comparisons were made with normal pregnancy controls, all of whom were managed in the same High Risk Obstetric Unit.

\section{Methods}

All women with pregnancies associated with renal transplantation and followed by the High Risk Obstetric Unit at the John Radcliffe Hospital, Oxford, between 1986 and 1996, were identified by a computerised search of the Unit database. 'High risk' normal pregnancy controls, with a history of either idiopathic recurrent miscarriage or foetal loss or pre-eclampsia in previous pregnancies, were also identified by a search of the same database. Controls were selected based on the following criteria: no history of a haematological disorder, antenatal $\mathrm{BP}<140 / 90 \mathrm{mmHg}$, no antenatal proteinuria or known renal disease, term delivery and birthweight appropriate for gestational age (GA). These 'high risk' normal pregnancy controls were matched to transplant cases according to age ( $\pm 4 \mathrm{yr}$ ), smoking (yes/no) and parity $( \pm 1)$.

In order to examine the 'normality' of normal pregnancy controls who had been referred to a High Risk Obstetrics Unit, 'general antenatal' pregnancy controls were also sought (prospectively) from general antenatal clinics at the same institution. They were selected and matched to cases according to the same criteria as for "high risk' normal pregnancy controls. Similar results would justify use of 'high risk' normal pregnancy controls who were recruited and managed in the same way as cases.
For transplant cases and 'high risk' normal pregnancy controls, standardised forms were used to collect the following background medical data by retrospective hospital chart review: maternal demographics (e.g. age, parity), history of renal disease, presence of pre-existent hypertension, baseline (pre-pregnancy) creatinine, other medical history, obstetrical history and immunosuppressant and other drug therapy. For 'general antenatal' normal pregnancy controls, the same information was collected by prospective chart review.

Collection and freezing of serial antenatal and postnatal serum have been routine in the Unit since the mid-1980s. Routine collection periods have been as follows: $\leq 17,17-22,23-28,29-34$ and 35-40 wk gestation, as well as both $2-5$ days and $6 \mathrm{wk}$ postpartum. In addition to the GA at which the frozen serum was taken, the following laboratory results (corresponding to the same serum sample) were abstracted from hospital records: $\mathrm{Hb}(\mathrm{g} / \mathrm{L})$ (as Hct was not available for most patients), mean cell volume (MCV) of red cells, platelet count $\left(\times 10^{9} / \mathrm{L}\right)$, creatinine $(\mu \mathrm{M})$, uric acid $(\mu \mathrm{M})$, dipstick proteinuria greater than trace, mid-stream urine (MSU) culture result (growth/no growth; organism if relevant) and 24-h urinary protein $(\mathrm{g})$. Blood film and reticulocyte counts were not available. There was insufficient information on creatinine clearance to be useful and cyclosporine A (CsA) measurements could not be used as they were not timed relative to ingestion of the drug.

Serum samples that had been stored at $-20^{\circ} \mathrm{C}$ were allowed to defrost, for this first time, at room temperature. All assays, except serum transferrin receptor protein (TfR), were performed and the samples were refrozen at $-20^{\circ} \mathrm{C}$ and shipped to Belgium where they were similarly defrosted, assayed for TfR and refrozen. No samples were lost. All samples were assayed for serum EPO, using a chemiluminescence immunoassay (Nichols Institute Diagnostic Ltd., Essex, UK) with results expressed in $\mathrm{U} / \mathrm{L}$; the intra- and inter-assay coefficients of variation $(\mathrm{CV})$ were 5.5 and $6.7 \%$, respectively. Only the first and last antenatal serum samples were assayed for ferritin, folate, vitamin B12 and TfR. Soluble TfR are closely related to the number of red blood cell precursors in the bone marrow and provide a surrogate marker for the rate of erythropoiesis, which is reliable in the absence of severe iron deficiency (which elevates TfR values) (7); soluble TfR levels are particularly useful for detection of multiple mechanisms of anaemia as can exist among pregnant patients with renal transplantation. Serum ferritin levels were 
assayed using a two-site incubation immunoradiometric assay (Bio-Rad Laboratories Ltd., Herts, UK) expressed in $\mu \mathrm{g} / \mathrm{L}$; the intra- and inter-assay CV were 4.2 and $11.1 \%$, respectively. Serum folate levels were determined using a modification of the chloramphenicol-resistant Lactobacillus caseii method (8) and expressed in $\mu \mathrm{g} / \mathrm{L}$; the intra- and inter-assay CV were 4.0 and $11.5 \%$, respectively. Vitamin B12 was assayed using a non-boil radioimmunoassay kit (Ortho-Clinical Diagnostics, Amersham, Buckinghamshire, UK), with the results expressed in $\mathrm{ng} / \mathrm{L}$; the intra- and inter-assay CV were 4.9 and $13.1 \%$, respectively. In accordance with standard procedure, each assay included both internal and external control samples. TfR was assayed using an ELISA $(9,10)$ in which each sample was run in duplicate; the intra- and inter-assay CV were 4.3 and $8.1 \%$, respectively.

The following outcomes were abstracted from hospital records: pregnancy outcome (i.e. miscarriage, elective termination, intrauterine foetal death, live birth, neonatal death), major malformations (defined as those having a major impact on structure or function (11)), development of preeclampsia (defined as $\mathrm{BP} \geq 140 / 90 \mathrm{mmHg}, \geq 0.3 \mathrm{~g}$ of proteinuria by $24-\mathrm{h}$ collection and/or oedema (12)), new antenatal (isolated) hypertension (i.e. $\mathrm{BP} \geq 140 / 90 \mathrm{mmHg}$ ), worsening of pre-existent hypertension (to $\geq 140 / 90 \mathrm{mmHg}$ ) without proteinuria, maternal pregnancy complications (e.g. urinary tract infection, renal allograft rejection), rise in antenatal and postnatal creatinine by $15 \%$ (from the first antenatal sample, to a value $>80$ $\mu \mathrm{M}$ (13)), GA at delivery (wk), prematurity (i.e. $<37$ wk gestation), birthweight (BW) (g), small for gestational age (SGA) infants (i.e. $<5$ th percentile), method of delivery, neonatal health problems (defined as those which prolonged hospital stay) and long-term renal outcome (e.g. renal allograft rejection or graft loss).

The primary outcome of interest was the relationship between serum EPO and $\mathrm{Hb}$. However, a two-way analysis of variance with repeated measures was first performed on one factor (GA) to assess the relationship of serum EPO or $\mathrm{Hb}$, with both patient group and GA. Given that measurements of EPO and $\mathrm{Hb}$ were made in time intervals that were not equal for all women, an unequally spaced repeated measurements design was used in which the spatial power law modelled the time series covariance structure of the repeated measurements.

A detectable relationship between GA and either serum EPO or $\mathrm{Hb}$ prompted examination of the relationship between them within GA categories. Within each GA category, the equation from the linear regression of log [serum EPO] versus $\mathrm{Hb}$ (5) among normal pregnancy controls was used to calculate 'predicted' values of log [serum EPO] from the $\mathrm{Hb}$ values of transplant cases. For transplant cases, a linear regression was performed of the observed over predicted $(\mathrm{O} / \mathrm{P})$ values of $\log$ [serum $\mathrm{EPO}$ ] versus $\mathrm{Hb}$. A slope that was significantly different from zero was taken to reflect a different relationship between log [serum EPO] and $\mathrm{Hb}$ than that seen among normal pregnancy controls. $\mathrm{p}<0.05$ was considered statistically significant for all analyses. Analyses were performed using SAS for IBM-compatible computers or GraphPad Prism 2.01 (GraphPad Software, San Diego, CA).

Of secondary interest were changes, from first to last antenatal sample, in: i) platelets, as a marker of the adequacy of other cell lines, ii) $\mathrm{MCV}$, iii) serum ferritin, iv) serum folate, v) serum B12, vi) serum TfR and vii) serum creatinine. Obstetric outcomes and maternal medical complications were also compared between groups. Betweengroup comparisons were made by Student's t-test or Mann-Whitney U-test (for continuous data) and $\chi^{2}$ or Fisher's exact test (for categorical data).

\section{Results}

Baseline demographics

Twenty-four renal transplant cases, with 30 pregnancies, were identified and included in the study. The indications for renal transplantation were reflux nephropathy $(\mathrm{n}=11,1 / 11$ nephrectomy of native kidneys), vasculitis including systemic lupus erythematosus $(\mathrm{n}=5)$, chronic glomerulonephritis $(\mathrm{n}=4)$, familial nephrosis $(\mathrm{n}=3)$, congenital malformations $(\mathrm{n}=2)$, focal segmental glomerulosclerosis $(n=2)$, polycystic kidney disease $(n=1)$ and unknown $(\mathrm{n}=2)$. The transplant to conception interval was (median [range]) 33.5 [4, 189] months. Cadaveric (14 [47\%]) and living related donor (15 [50\%]) transplants were equally common; the nature of one transplant was unknown. Only $6(20 \%)$ transplants had been followed by an episode of acute rejection within the first 3 months post-operatively. Immunosuppressants were most commonly azathioprine, CsA and prednisone $(\mathrm{n}=13)$, followed in frequency by azathioprine and prednisone $(\mathrm{n}=7)$, CsA and prednisone $(\mathrm{n}=5)$, azathioprine and CsA $(n=4)$ and azathioprine alone $(n=1)$.

Thirty 'high risk' normal pregnancy controls, with a history of either pre-eclampsia in a previous pregnancy $(\mathrm{n}=17)$ or unexplained recurrent miscarriage $(n=10)$, stillbirth $(n=2)$ or neonatal death $(n=1)$ were identified. Their $\mathrm{Hb}$, serum EPO, platelet counts, serum ferritin, serum folate, 
serum B12 and TfR were found not to differ from those of the 16 'general antenatal' normal pregnancy controls (data not presented). Therefore, only 'high risk' normal pregnancy controls were compared with renal transplant cases for the remainder of the analyses.

Table 1 shows that there were no differences between renal transplant cases or 'high risk' normal pregnancy controls in terms of maternal age at delivery, ethnicity, smoking or GA at booking. Cases were more likely to be primiparous (whereas controls were more likely to have had one previous pregnancy) and have pre-existent hypertension. Most (17/20) with hypertension had been treated with antihypertensive medication before pregnancy, usually with a beta-blocker (13/17). One case was on captopril, which was discontinued when pregnancy was diagnosed. Cases also had higher baseline serum creatinine and serum uric acid and there was a trend toward higher 24-h urinary protein. Three women had baseline serum creatinine concentrations greater than $125 \mu \mathrm{M}$ (i.e. 146, 167 and $185 \mu \mathrm{M})$.

Table 2 shows that at baseline, renal transplant cases also had lower $\mathrm{Hb}$ concentrations than normal pregnancy controls. The GA (mean \pm SD) at which the first sample was stored was not significantly different between transplant cases and 'high risk' normal pregnancy controls. Cases had higher MCV and serum ferritin, but similar serum folate, B12, EPO and TfR values. Platelet counts did not differ between groups. Equivalent numbers of transplant cases and normal pregnancy controls took iron supplements during the pregnancy (i.e. $21 / 30$ vs. 16/30 [controls]; $\mathrm{p}=0.18$ ). No cases or controls reported bleeding complications.

\section{Erythropoiesis}

Fig. 1 shows that from baseline throughout pregnancy, the $\mathrm{Hb}$ of renal transplant cases remained significantly lower than that of 'high risk' normal pregnancy controls $(\mathrm{p}=0.0001)$. At some point in gestation, $\mathrm{Hb}$ was less than $100 \mathrm{~g} / \mathrm{L}$ among 22 $(74 \%)$ transplant cases (vs. 4 [13\%] [controls]) $(\mathrm{p}<$ $0.0001)$. There were few serum samples available before $17 \mathrm{wk} \mathrm{GA}$; therefore, postnatal $\mathrm{Hb}$ values were examined as surrogates for antenatal values. Postnatal $\mathrm{Hb}$ values were available for 20 of the 22 transplant cases with a antenatal $\mathrm{Hb}$ less than 100 $\mathrm{g} / \mathrm{L}$; only 1 had a Hb less than $100 \mathrm{~g} / \mathrm{L}$, compared with no controls $(p=0.40)$. No cases or controls were transfused postnatally.

Fig. 2 shows that among both transplant cases and 'high risk' normal pregnancy controls, serum EPO concentration increased with advancing GA $(\mathrm{p}=0.0003)$, but there was no difference between groups $(p=0.75)$. In order to account for the GA effect on serum EPO, the relationship between serum EPO and $\mathrm{Hb}$ was examined within three $\mathrm{GA}$ categories: < 17, 17-28 and > $>29$ wk gestation to reflect early, mid- and late pregnancy.

Using data from 'high risk' normal pregnancy controls, regression equations were obtained for $\log$ [serum EPO] versus $\mathrm{Hb}$ for both the 17-28 wk $(2.95-[0.14 \times \mathrm{Hb}] ; \mathrm{n}=46$ samples $)$ and $29-42 \mathrm{wk}$ categories $(2.23-[-0.07 \times \mathrm{Hb}] ; \mathrm{n}=52$ samples). The analysis was not possible for early pregnancy given the few available samples. Fig. $3 a$ and $b$ shows that the $\mathrm{O} / \mathrm{P}$ ratio of $\log$ [serum EPO] for transplant cases differed significantly from zero, for both the 17-28 wk (slope \pm SEM: $0.010 \pm$ $\left.0.002 ; \quad \mathrm{r}^{2}=0.30 ; \quad \mathrm{p}<0.0001\right)$ and $29-42 \quad \mathrm{wk}$ cateogories $\quad\left(0.006 \pm 0.003 ; \quad \mathrm{r}^{2}=0.08 ; \mathrm{p}=0.02\right)$. This indicated a relationship between log [serum

Table 1. Baseline characteristics

\begin{tabular}{|c|c|c|c|c|}
\hline & Reference range ${ }^{a}$ & $\begin{array}{l}\text { Renal transplant pregnancies } \\
(n=30)\end{array}$ & $\begin{array}{l}\text { 'High risk' normal pregnancies } \\
(n=30)\end{array}$ & $p^{b}$ \\
\hline Maternal age at EDD (yr) (mean \pm SD) & $\mathrm{n} / \mathrm{a}$ & $26.7 \pm 5.0$ & $28.7 \pm 5.0$ & 0.12 \\
\hline Caucasian (\%) & $\mathrm{n} / \mathrm{a}$ & $29(97)$ & $30(100)$ & 0.31 \\
\hline Primiparous (\%) & $\mathrm{n} / \mathrm{a}$ & $20(67)$ & $7(24)^{c}$ & 0.01 \\
\hline Nonsmokers (\%) & $\mathrm{n} / \mathrm{a}$ & $24(80)$ & $24(80)$ & 1.00 \\
\hline GA at booking (wk) (median [range]) & $\mathrm{n} / \mathrm{a}$ & $10.5[6,34]$ & $11.0[5,27]$ & 0.74 \\
\hline Pre-existent hypertension (\%) & $\mathrm{n} / \mathrm{a}$ & $20(67)$ & $0(0)$ & $<0.001$ \\
\hline Serum creatinine $(\mu \mathrm{M})$ (median [range]) & $50-100 \mu \mathrm{M}$ & $100.5[56.0,185.0]$ & $58.0[43.0,79.0]$ & $<0.0001$ \\
\hline Serum uric acid $(\mu \mathrm{M})$ (median [range]) & $120-420 \mu \mathrm{M}$ & $337.0[171.0,609.0]$ & $199.0[122.0,320.0]$ & $<0.0001$ \\
\hline 24-h urinary protein (g) (median [range]) & $<0.3 \mathrm{~g} / 24 \mathrm{~h}^{\mathrm{d}}$ & $0.1[0.1,0.4]$ & $0.1[0.1,0.2]$ & 0.052 \\
\hline
\end{tabular}

${ }^{\text {a }}$ Range for non-pregnancy unless otherwise stated.

b Values in bold are statistically significant at $p<0.05$.

${ }^{\mathrm{C}}$ Data missing for one pregnancy.

${ }^{\mathrm{d}}$ Normal range for pregnancy; lower limit of the assay is $100 \mathrm{mg}$ per $24 \mathrm{~h}$.

EDD (expected date of delivery), GA (gestational age). 


\begin{tabular}{|c|c|c|c|c|}
\hline & Reference range for non-pregnancy & $\begin{array}{l}\text { Renal transplant pregnancies } \\
(n=30) \text { at } 16.6 \pm 3.9 \mathrm{wk}\end{array}$ & $\begin{array}{l}\text { 'High risk' normal pregnancies } \\
(n=30) \text { at } 18.9 \pm 3.9 \text { wk }\end{array}$ & $p^{a}$ \\
\hline $\mathrm{Hb}(\mathrm{g} / \mathrm{L})$ (median [range]) & $>110 \mathrm{~g} / \mathrm{L}^{\mathrm{b}}$ & $101[65,129]$ & $116[106,150]$ & 0.004 \\
\hline $\operatorname{MCV}\left(\mu \mathrm{M}^{3}\right)$ (median [range]) & $76-100 \mu \mathrm{M}^{3}$ & $93.3[85.4,107.6]$ & $89.7[80.9,99.4]$ & 0.005 \\
\hline Platelet count $\left(\times 10^{9} / \mathrm{L}\right)$ (median [range]) & $150-450 \times 10^{9} / \mathrm{L}$ & $258.0[106,345]$ & $261.0[151.0,464.0]$ & 0.79 \\
\hline Serum ferritin $(\mu \mathrm{g} / \mathrm{L})$ (median [range]) & $14-200 \mu \mathrm{g} / \mathrm{L}$ & $38.0[10.0,267.0]$ & $12.0[4.0,69.0]$ & 0.004 \\
\hline Serum folate $(\mu \mathrm{g} / \mathrm{L})$ (median [range]) & $2.1-28.0 \mu \mathrm{g} / \mathrm{L}$ & $8.2[4.4,18.0]$ & $8.1[3.0,18.0]$ & 0.89 \\
\hline Serum B12 (ng/L) (median [range]) & $>150 \mathrm{ng} / \mathrm{L}$ & $211.0[76.0,457.0]$ & $204.0[130.0,472.0]$ & 0.70 \\
\hline Serum erythropoietin (U/L) (median [range]) & $2-17.0 \mathrm{U} / \mathrm{L}$ & $15.2[2.6,84.6]$ & $15.7[6.4,41.0]$ & 1.00 \\
\hline TfR $(\mathrm{ng} / \mathrm{ml})$ (median [range]) & $2900-7100 \mathrm{ng} / \mathrm{mL}$ & $3439.0[1658.0,5912.0]$ & $2882.0[1581.0,6687.0]$ & 0.12 \\
\hline
\end{tabular}

a Values in bold are statistically significant at $p<0.05$

${ }^{\mathrm{b}}$ As per the World Health Organization.

$\mathrm{Hb}$ (haemoglobin), MCV (mean red cell volume), TfR (transferrin receptor protein).

EPO] and $\mathrm{Hb}$ that was different from that seen among normal pregnancy controls, for both GA categories.

One renal transplant case received two units of packed red blood cells for a $\mathrm{Hb}$ of $59 \mathrm{~g} / \mathrm{L}$ and $4 \mathrm{wk}$ later, went on to receive exogenous EPO with good effect. Prior to EPO administration at 19 wk gestation, her serum EPO and $\mathrm{Hb}$ were $7.8 \mathrm{U} / \mathrm{L}$ and 60 $\mathrm{g} / \mathrm{L}$, respectively. After exogenous EPO administration, her serum EPO and $\mathrm{Hb}$ peaked at 21.4 $\mathrm{U} / \mathrm{L}$ and $92 \mathrm{~g} / \mathrm{L}$ by 28 wk gestation. Her data were not influential in the analyses. Administration of EPO was not associated with poorly controlled hypertension, although the patient did go on to develop increasing hypertension and proteinuria (maximum $0.98 \mathrm{~g} / \mathrm{d}$ ). She was induced at $36 \mathrm{wk}$ gestation and had a vaginal delivery of a infant weighing $2724 \mathrm{~g}$ (50th percentile for GA). He had Apgars of 3,6 and 9 at 1,5 and $10 \mathrm{~min}$, respectively and required intubation. There was no neonatal polycythemia.

Only the change (from the first to last antenatal samples) in TfR, platelets and creatinine differed between groups; no differences were seen in the change in serum ferritin, serum folate, serum B12 or MCV (data not presented). Cases showed a smaller rise in TfR levels (median change [range] of 481 [ $-1471,2780]$ vs. 1119 [ $-698,4195]$ controls $\mathrm{U} / \mathrm{L} ; \mathrm{p}=0.005)$, as well as larger rises in platelet count $(21[-96,202]$ vs. $-12[-102,152]$ [controls $\left.] \times 10^{9} / \mathrm{L} ; \mathrm{p}=0.003\right)$ and creatinine concentration $(12.38[-7.07,6.19]$ vs. $1.77[-14.14,30.94]$ [controls] $\mu \mathrm{M} ; \mathrm{p}=0.0002)$.

\section{Pregnancy and maternal outcomes}

Table 3 shows that pregnancy outcome was favourable for both groups. Among renal transplant pregnancies, there were two intrauterine foetal deaths (at 29 and 35 wk gestation); prematurity,
SGA infants and neonatal health problems (i.e. special care baby unit admission due to prematurity $[n=8]$ and sepsis $[n=1])$ were also more frequent. Prematurity among transplant pregnancies was most commonly iatrogenic $(\mathrm{n}=11)$ and most commonly for pre-eclampsia $(n=7)$. Four women with renal transplants had two or three pregnancies, which did not appear to be more complicated than the first.

Table 3 also shows that transplant cases suffered an excess of medical complications such as pregnancy hypertension, urinary tract infections or asymptomatic bacteruria, rise in antenatal serum creatinine concentration and increasing proteinuria. Twenty transplant cases developed new/worsening hypertension; overall, $19(63 \%)$ developed hypertension and proteinuria that were thought to be indicative of pre-eclampsia. Just over half of renal transplant cases developed proteinuria, with a peak (median [range]) value of 500 [200, 5900] $\mathrm{mg} / 24 \mathrm{~h}$. Most transplant cases who developed antenatal urinary tract infections or asymptomatic bacteruria did so recurrently, i.e. on two (8 vs. 1 [control]), three (1 vs. 0 [control]), four (1 vs. 0

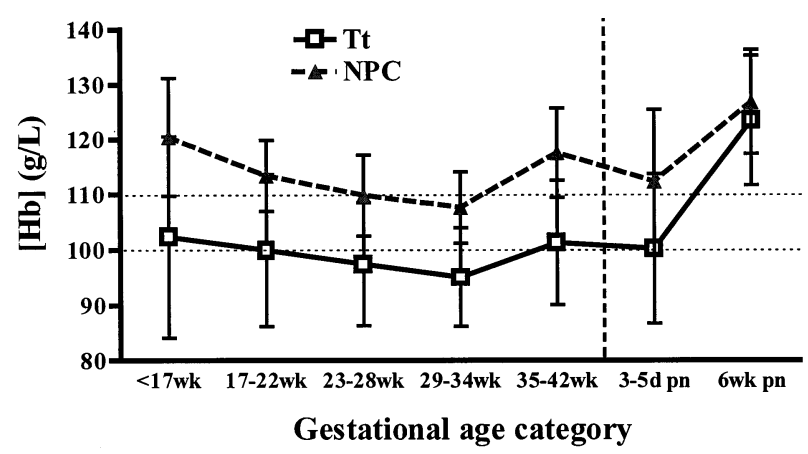

Fig. 1. Gestational age versus $\mathrm{Hb}($ mean $\pm \mathrm{SD})$ for renal transplant cases (Tt) and normal pregnancy controls (NPC). Both antenatal, as well as postpartum day $3-5$ and wk 6 are presented. 


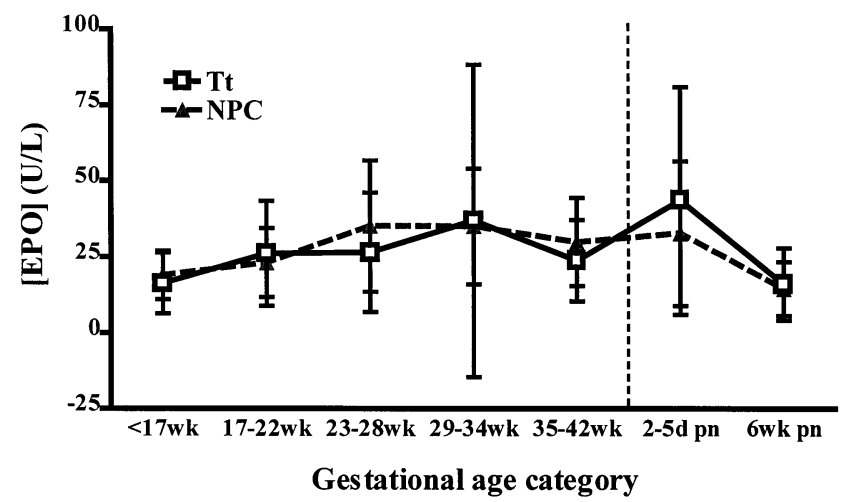

Fig. 2. Gestational age versus concentration of serum erythropoietin ([EPO]) (mean $\pm \mathrm{SD})$ for renal transplant cases $(\mathrm{Tt})$ and normal pregnancy controls (NPC). Both antenatal as well as postpartum day $3-5$ and wk 6 are presented.

[control]) or five occasions (2 vs. 0 [control]). Antibiotic prophylaxis was instituted in 1 case.

Of note, haematuria developed among most renal transplant cases and more frequently than among 'high risk' normal pregnancy controls; none of the women had a concurrent urinary tract infection or identifiable renal stone disease and in no instance were red or white blood cell casts identified. Graft loss occurred among 4 renal transplant cases $(13 \%)$, due to a failed transplant artery repair (at 5 months postnatally) or rejection $(n=3$; at 6,21 and 60 months postpartum).

\section{Discussion}

The history of renal transplantation and pregnancy dates back 30 years. At present, about 1/50 women of child-bearing age with a functioning renal allograft become pregnant. These pregnancies are recognised to be more complicated, both obstetrically and medically (6). This single centre retrospective cohort of women, with predominantly mild renal impairment and hypertension, experienced rates of obstetric and medical complications comparable to those described in the literature (6). However, what was also demonstrated in this study, and not previously shown, was the fact that these pregnancies are also frequently complicated by anaemia.

$\mathrm{Hb}$ values less than $100 \mathrm{~g} / \mathrm{L}$ occurred among most $(74 \%)$ renal transplant pregnancies, but among few $(13 \%)$ normal pregnancy controls. Postnatal anaemia was not a problem among either transplant cases or controls. When assayed between 17 and $42 \mathrm{wk}$ gestation and compared with normal pregnancy controls, transplant cases were shown to have serum EPO levels that were inappropriately low for concomitant $\mathrm{Hb}$ values; although 1 transplant case received exogenous
EPO, the latter would not change the relationship between serum EPO and $\mathrm{Hb}$ (14) and her data were not influential. The rate of erythropoiesis, as reflected by serum TfR levels, was also blunted among renal transplant cases given that TfR levels failed to rise as much as those among normal pregnancy controls, among whom this rise was consistent with the erythropoiesis of normal pregnancy.

Impaired erythropoiesis among women with renal transplantation in pregnancy may result from a number of factors. There was no evidence that transplant cases were deficient in iron, folate or vitamin B12. In fact, serum ferritin was actually higher among transplant cases. Despite this, they went on (inappropriately) to receive supplemental iron in most cases. There was no global bone marrow dysfunction, as indicated by similar platelet counts at baseline and actually higher platelet counts among transplant cases before delivery; this occurred despite a higher incidence of proteinuric hypertension. A toxic effect of azathioprine therapy on erythropoiesis must be considered (15). Most transplant cases (25 [83\%]) were on azathioprine and had higher MCV values throughout pregnancy, consistent with azathioprine-induced bone marrow toxicity. However, azathioprine should not impair renal release of EPO. CsA, which may decrease renal production of EPO, was taken by 22/30 transplant cases (16). Although renal transplant patients may be more plasma volume expanded during pregnancy, explaining both lower $\mathrm{Hb}$ and EPO values, the relationship between the two should not have changed. There was no evidence of haemolysis or excessive blood loss to account for anaemia among transplant cases.

Impaired renal function must be considered as an aetiological factor in the demonstrated impaired erythropoiesis among renal transplant cases. Support for the importance of renal graft function (17) and inadequate production of EPO in the pathogenesis of anaemia in renal transplant pregnancies comes from the following data: i) a slightly elevated but inappropriately low serum EPO in 1 such patient $(18)$, ii) a gradual increase in EPO concentration during normal pregnancy (6), iii) higher exogenous EPO requirements by some haemodialysis patients during pregnancy (19) and iv) the response of anaemic transplant patients to exogenous EPO $(5,20)$. However, there are 3 reported cases of transplant patients with stable creatinine concentrations who required exogenous EPO during pregnancy $(17,20)$. Some but not all of these women were on azathioprine, which could contribute to anaemia through bone marrow suppression. 
Not surprisingly, transplant cases in this study were shown to have higher serum creatinine concentrations (at baseline and before delivery), 24-h urinary protein excretion and a rise in antenatal serum creatinine by more than $15 \%$. However, most cases had only a small rise in serum creatinine during pregnancy, with only 3 having a creatinine $>200 \mu \mathrm{M}$ prior to delivery. Anaemia is not usually seen at the level of renal function seen among transplant cases in this study.

The finding of unexplained haematuria, which was confirmed by urine microscopy and seen among both (the majority of) renal transplant cases and (17\% of) normal pregnancy controls, was an unexpected finding and remains unexplained. This was not associated with urinary tract infection, renal stone or evidence of rejection.

Although this study is the first to report on erythropoiesis among renal transplant recipients who become pregnant, it has many limitations. It is retrospective in design. Many data were abstracted from hospital records. Neither antenatal nor early pregnancy $\mathrm{Hb}$ values were available, such that postnatal values had to be used as surrogates. Serum folate, not RBC folate, could be assayed. Reticulocyte counts and Hct were not available from the hospital charts. Most cases were taking azathioprine, whereas many transplant patients today are on non-azathioprine-containing drug regimes. Most cases were also taking CsA, so it was not possible to examine whether this medication had an impact on erythropoiesis independent of renal function. Finally, we have no information on other growth factors, such as interleukin-3, which also regulate erythropoiesis and may be altered by immunosuppressant therapy.

In summary, this retrospective cohort study from a single tertiary care centre, demonstrates that anaemia frequently complicates the pregnancies of women with renal transplantation. Even in

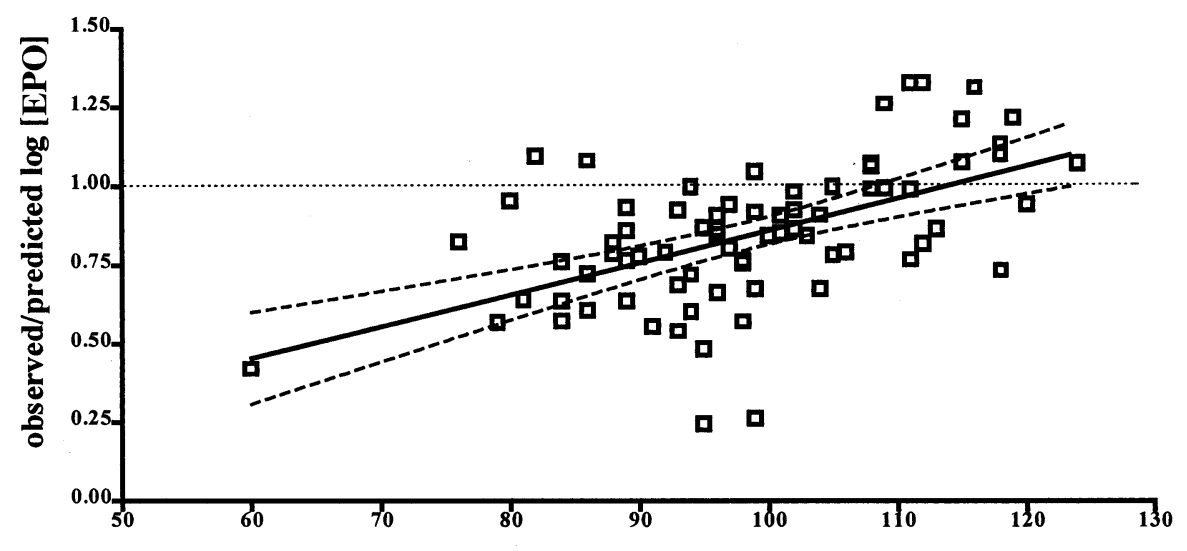

(a)

[haemoglobin] (g/L)

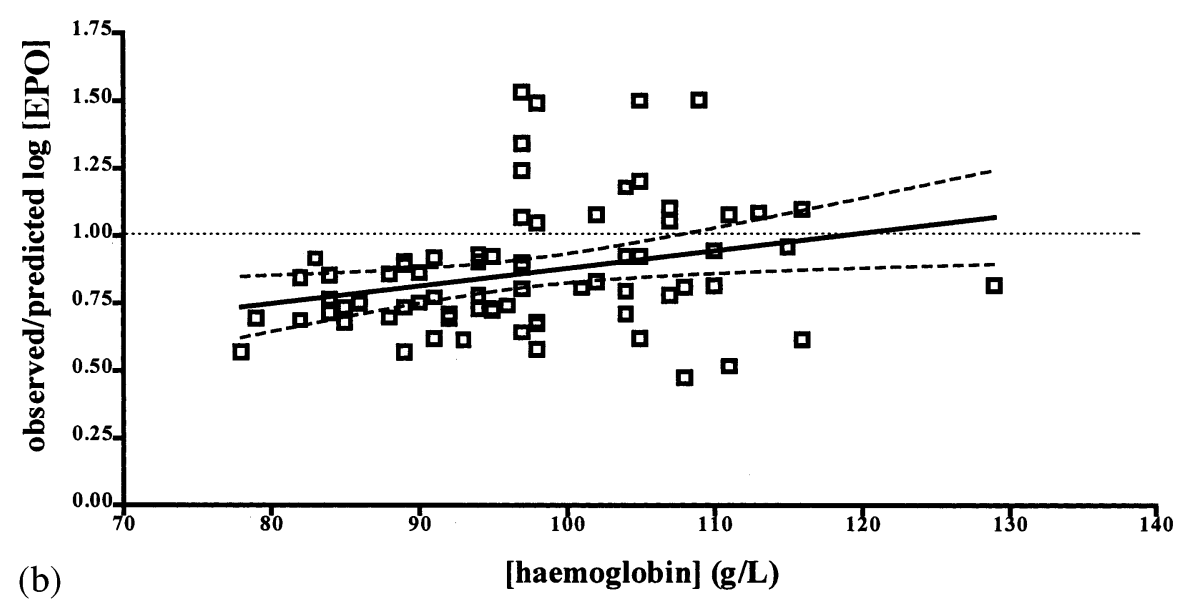

Fig. 3. (a) $\mathrm{O} / \mathrm{P}$ (observed over predicted) ratio of $\log$ \{serum erythropoietin concentration [serum EPO]) versus $\mathrm{Hb}$, for transplant cases, for 17-28 wk gestation. Predicted values of $\log$ [serum EPO] for transplant cases were calculated from the regression of log [serum EPO] versus $\mathrm{Hb}$ for normal pregnancy controls. The slope differs significantly from zero ( $<<0.0001)$. (b) $\mathrm{O} / \mathrm{P}(\mathrm{observed}$ over predicted) ratio of $\log$ (serum erythropoietin concentration [serum EPO]) versus Hb, for transplant cases, for 29-42 weeks' gestation. Predicted values of $\log$ [serum EPO] for transplant cases were calculated from the regression of log [serum EPO] versus $\mathrm{Hb}$ for normal pregnancy controls. The slope differs significantly from zero $(\mathrm{p}=0.02)$. 


\begin{tabular}{|c|c|c|c|}
\hline & $\begin{array}{l}\text { Renal transplant pregnancies } \\
(n=30)\end{array}$ & $\begin{array}{l}\text { 'High risk' normal pregnancies } \\
(\mathrm{n}=30)\end{array}$ & $p^{a}$ \\
\hline \multicolumn{4}{|l|}{ Obstetric outcomes } \\
\hline Pregnancy outcome (\%) live births & $28(93)$ & $30(100)$ & 0.49 \\
\hline Major malformations $(\%)^{\mathrm{b}}$ & $3(10)$ & $2(7)$ & 0.66 \\
\hline Gestational age at delivery (wk) (median [range]) & $36.0[29.0,39.0]$ & $39.0[37.0,41.0]$ & $<0.001$ \\
\hline Prematurity (\%) & $17(57)$ & $1(3)$ & $<0.001$ \\
\hline Birthweight (g) (median [range]) & $2526[550,3540]$ & $3174[2660,4047]$ & $<0.009$ \\
\hline SGA infants < $<$ th percentile (\%) & $5(17)$ & $0(0)$ & 0.05 \\
\hline \multicolumn{4}{|l|}{ Method of delivery (\%) } \\
\hline Induction of labour (\%) & $17(57)$ & $10(33)$ & 0.12 \\
\hline Caesarean section (\%) & $12(40)$ & $9(30)$ & 0.59 \\
\hline Neonatal health problems (\%) & $9(30)$ & $1(3)$ & 0.01 \\
\hline \multicolumn{4}{|l|}{ Maternal outcomes } \\
\hline Pregnancy hypertensionc (\%) & $28(93)$ & $0(0)$ & $<0.001$ \\
\hline AN positive urine culture (\%) & $19(63)$ & $3(10)$ & $<0.001$ \\
\hline Rise in AN creatinine by $15 \%^{\mathrm{d}}(\%)$ & $14(47)$ & $2(7)$ & $<0.001$ \\
\hline Rise in PN creatinine by $15 \%(\%)$ & $16(53)$ & $17(71)$ & 1.0 \\
\hline $24-h$ urinary protein > $0.3 \mathrm{~g}(\%)$ & $16(53)$ & $0(0)$ & $<0.001$ \\
\hline Haematuria (\%) & $20(67)$ & $5(17)$ & $<0.001$ \\
\hline
\end{tabular}

a Values in bold are statistically significant at $p<0.05$

${ }^{b}$ Malformations among renal transplant cases were reflux nephropathy and hypospadias $(n=2)$ and among controls were bilateral hydrocoeles and polydactyly of the foot.

${ }^{c}$ Defined as either pre-eclampsia or worsened pre-existent or new hypertension.

${ }^{d}$ Rise in creatinine was defined by a $15 \%$ increase, from the first antenatal measurement, to $>80 \mu \mathrm{M}$.

AN (antenatal), PN (postnatal).

the absence of serious deterioration in renal function, the transplant kidney may be unable to increase production of EPO and stimulate erythropoiesis sufficiently to meet the increased demands of pregnancy. If treatable causes of anaemia have been ruled out, then consideration should be given to treatment with exogenous EPO, which does not cross the term placenta in vitro (21).

\section{Acknowledgements}

Our sincere thanks to Davina Buckley whose diligence and careful handling of serum samples made this study possible. Thanks also to Tansy Cheston, June Jennings, Vibeke Mannion and the rest of the Silver Star Unit Team for their meticulous record-keeping. Special thanks, as always, to Professor CWG Redman for the foresight to prospectively collect serum samples and patient data which made this study possible and for his considered advice and academic support. LAM was supported by a Duncan Gordon Fellowship of the Hospital for Sick Children Research Foundation and a Detweiler Travelling Fellowship from the Royal College of Physicians and Surgeons of Canada. Funding was provided by the Oxford Regional Health Authority, Janssen-Cilag Ltd., UK and the FNRS, Belgium.

\section{References}

1. World Health Organization. Nutritional anemias. Technical Report Series No. 503. Geneva, 1972.
2. LeTSKy EA. Blood volume, haematinics, anaemia. In: de Swiet M, ed. Medical Disorders in Obstetric Practice, 3rd edition. Oxford: Blackwell Science Ltd., 1995: 33.

3. LACOMBE D. Resistance to erythropoietin. New Engl J Med 1996: 334: 660.

4. ERslev AJ. Erythropoietin. New Engl J Med 1991: 324: 1339.

5. Beguin Y, Lipscei G, Thoumsin H, Fillet G. Blunted erythropoietin production and decreased erythropoiesis in early pregnancy. Blood 1991: 1: 89.

6. DAVISON JM. Pregnancy in renal allograft recipients: problems, prognosis and practicalities. In: Lindheimer MD, Davison JM, eds. Bailliere's Clinical Obstetrics and Gynaecology. Renal Disease in Pregnancy. London: Bailliere Tindall, 1994: 501.

7. Cazzola M, Beguin Y. New tools for clinical evaluation of erythron function in man. Br J Haematol 1992: 80: 278.

8. Walter AH, Mullin DL. Diagnosis of folate deficiency. Association of Clinical Pathologists Broadsheet 1973: 79: 1.

9. Huebers ha, Beguin Y, Pootrakul P, Einspahr D, FINCH CA. Intact transferrin receptors in human plasma and their relation to erythropoiesis. Blood 1990: 75: 102.

10. Beguin Y, Clemons G, Pootrakul P, Fillet G. Quantitative assessment of erythropoiesis and functional classification of anemia based on measurements of serum transferrin receptor and erythropoietin. Blood 1993: 81: 1067.

11. Marden PM, Smith DW, McDonald MJ. Congenital anomalies in the newborn infant, including minor variations. J Pediatr 1964: 64: 357.

12. Hughes EC (editor). Obstetric-Gynecologic Terminology. Davis: Philadelphia, 1972; 422.

13. Davison JM, Dunlop W, Ezimokhai M. Twenty-four hour creatinine clearance during the third trimester of normal pregnancy. Br J Obstet Gynaecol 1980: 87: 106. 
14. Goodnough LT, Price TH, Parvin CA, Friedman KD, Vogler WR, Khan N, Sacher R, Johnston M, Wissel M, Ciavarella D. Erythropoietin response to anemia is not altered by surgery or recombinant human erythropoietin therapy. Br J Haematol 1994: 87: 695.

15. Anastassiades E, Howart D, Howart JE. Influence of azathioprine on the ferrokinetics of patients with renal failure before and after treatment with erythropoietin. Nephron 1994: 67: 291.

16. VAnnucchi AM, Bost A, Grossi A, Guidi S, SACCARdi R, Rossi-FERRINI P. Down-modulation of serum erythropoeitin levels following cyclosporin A infusion. Bone Marrow Transpl 1994: 13: 497.

17. McGregor E, Stewart G, Junor BJR, Rodger RSC. Successful use of recombinant human erythropoietin in pregnancy. Nephrol Dial Transplant 1991: 6: 292.
18. Zeidan BS, Waltzer WC, Monheit AG, Rapaport FT. Anemia associated with pregnancy in a cyclosporinetreated renal allograft recipient. Transplant Proc 1991: 23: 2301.

19. Hou S, Orlowski J, Pahl M, Ambrose S, Hussey M, WONG D. Pregnancy in women with end-stage renal disease: treatment of anemia and premature labor. Am $\mathbf{J}$ Kidney Dis 1993: 21: 16.

20. Szurkowski M, Wiecek A, Kokot F, Daniel K. Safety and efficiency of recombinant human erythropoietin treatment in anemic pregnant women with a kidney transplant. Nephron 1994: 67: 242.

21. Malek A, Sager R, Eckardt KU, Bauer C, SCHNEIDER H. Lack of transport of erythropoietin across the human placenta as studied by an in vitro perfusion system. Pflugers Arch 1994: 427: 157. 